\title{
Two new stegosaur specimens from the Upper Jurassic Morrison Formation of Montana, USA
}

\author{
D. Cary Woodruff, David Trexler, and Susannah C.R. Maidment \\ Acta Palaeontologica Polonica 64 (3), 2019: 461-480 doi:https://doi.org/10.4202/app.00585.2018
}

Two partial skeletons from Montana represent the northernmost occurrences of Stegosauria within North America. One of these specimens represents the northernmost dinosaur fossil ever recovered from the Morrison Formation. Consisting of fragmentary cranial and postcranial remains, these specimens are contributing to our knowledge of the record and distribution of dinosaurs within the Morrison Formation from Montana. While the stegosaurs of the Morrison Formation consist of Alcovasaurus, Hesperosaurus, and Stegosaurus , the only positively identified stegosaur from Montana thus far is Hesperosaurus. Unfortunately, neither of these new specimens exhibit diagnostic autapomorphies. Nonetheless, these specimens are important data points due to their geographic significance, and some aspects of their morphologies are striking. In one specimen, the teeth express a high degree of wear usually unobserved within this clade-potentially illuminating the progression of the chewing motion in derived stegosaurs. Other morphologies, though not histologically examined in this analysis, have the potential to be important indicators for maturational inferences. In suite with other specimens from the northern extent of the formation, these specimens contribute to the ongoing discussion that body size may be latitudinally significant for stegosaurs-an intriguing geographical hypothesis which further emphasizes that size is not an undeviating proxy for maturity in dinosaurs.

Key words: Dinosauria, Thyreophora, Stegosauria, Jurassic, Morrison Formation, USA, Montana.

D. Cary Woodruff [sauropod4@gmail.com], Great Plains Dinosaur Museum and Field Station, 405 N 1st Ave E, Malta, MT 59538, USA; and Department of Ecology and Evolutionary Biology, University of Toronto; Royal Ontario Museum, 25 Willcocks Street, Room 3055, Toronto, M5S 3B2 Ontario, Canada. David Trexler [Dinoguy10@yahoo.com], Two Medicine Dinosaur Center, 120 2nd Ave S, Bynum, MT 59419, Bynum, MT, USA. Susannah C. R. Maidment [susannah.maidment@nhm.ac.uk], Department of Earth Sciences, Natural History Museum, Cromwell Rd, South Kensington, London SW7 5BD, UK. 
This is an open-access article distributed under the terms of the Creative Commons

Attribution License (for details please see creativecommons.org), which permits unrestricted use, distribution, and reproduction in any medium, provided the original author and source are credited.

Forf Full text $(1,742.7 \mathrm{kB})$ 